\title{
IMPORTANCE OF ENERGY MANAGEMENT IN BUILDINGS
}

\author{
Mile Medjugorac, Sonja Susac, Petar Maric \& Tino Filipovic
}
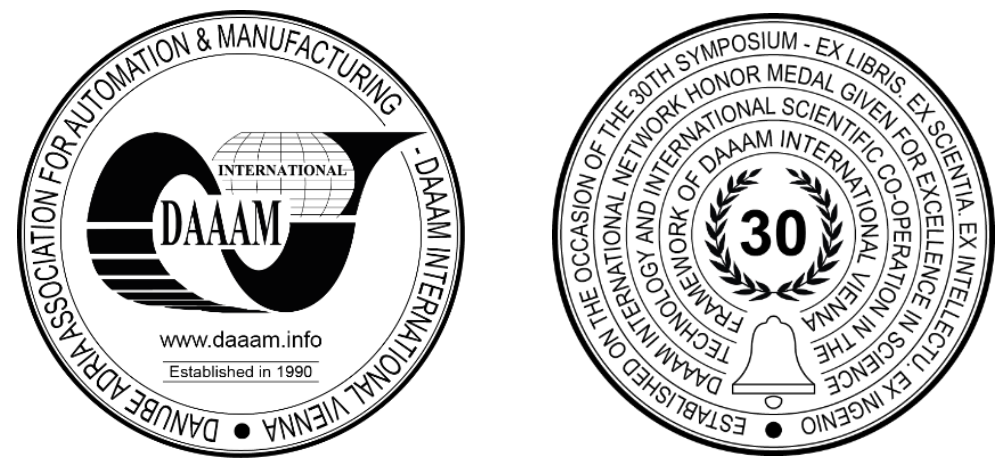

This Publication has to be referred as: Medjugorac, M[ile]; Susac, S[onja]; Maric, P[etar] \& Filipovic, T[ino] (2020). Importance of Energy Management in Buildings, Proceedings of the 31st DAAAM International Symposium, pp.08910898, B. Katalinic (Ed.), Published by DAAAM International, ISBN 978-3-902734-29-7, ISSN 1726-9679, Vienna, Austria

DOI: $10.2507 / 31$ st.daaam.proceedings.124

\begin{abstract}
In 2019, European Union presented Clean energy for all Europeans package with principle "energy efficiency first". By 2030, the target in energy efficiency is set to 32,5\% relative to baseline scenario established in 2007. Building energy management systems (BEMS) reduce energy consumption while increasing users' comfort and therefore are important in achieving energy efficiency target. BEMS are computer-based control systems that monitor and control the mechanical and electrical equipment in buildings such as heating and cooling systems, ventilation, lighting, power systems etc. These systems are also called building management systems (BMS); they connect the building elements back to a central computer to enable control of temperature, humidity, switching elements on/off etc. In the business building of JP EPHZHB d.d. Mostar in Tomislavgrad, two building management systems have been installed. One is a commercial, manufactured by Siemens, type Desigo CC. The second is a development project, developed through an international 3Smart project, called 3Smart EMS. The paper will present information on both systems and a comparison of energy consumption during the operation of both systems.
\end{abstract}

Keywords: Energy Efficiency; Renewable Energy Sources; Building Energy Management System; Desigo CC; 3Smart EMS;

\section{Introduction}

Energy efficient use of energy is important in achieving sustainable development. In 2007, the European Union set targets for 2020 and incorporated them into legislation in 2009 [1]: 20\% reduction of greenhouse gas emissions compared to the level of the $1990 \mathrm{~s}, 20 \%$ realization of the share of energy consumption obtained from renewable sources energy and $20 \%$ more energy efficient use or reduction of energy consumption compared to the 2007 projections.

A recent document of the European Union - Clean energy for all Europeans [2], puts energy efficiency first and sets goals for 2030: 40\% reduction of greenhouse gas emissions compared to the levels of the 1990s, 32\% realization of the share of energy consumption that is produced from renewable energy sources in energy consumption and 32,5\% more efficient energy use i.e. reduction of energy consumption compared to the projections from 2007. Accordingly, it is important to research and develop energy management systems with a properly designed management architecture [3]. Energy consumption of residential buildings increased mainly due to the use of heating, ventilation and air conditioning systems (HVAC) and due to user behavior. 
According to the International Energy Agency, residential and commercial buildings currently have $32 \%$ of final energy consumption [3] [4]. Since the energy consumption obtained by burning fossil fuels has a negative impact on climate change, it is imperative to ensure clean and efficient energy management systems in buildings. The requirements for improvement in energy consumption are threefold. Affordable energy, sustainable energy and better energy management infrastructure are needed. The main term for equipment used for energy management in buildings is Building Energy Management Systems (BEMS).

BEMS are computer-based control systems that control and monitor the mechanical and electrical equipment in buildings such as ventilation, heating, lighting, power systems, and so on [5]. The main goals of BEMS are to increase customer satisfaction by creating a comfortable and productive environment, and to reduce energy consumption, operating costs, and the negative impact on the environment through the reduction of carbon emissions.

Participating in the 3Smart project (acronym from Smart Building - Smart Grid - Smart City), JP Elektroprivreda HZHB d.d. Mostar has implemented 2 energy management systems in the office building in Tomislavgrad. One is a commercial system manufactured by Siemens - Desigo CC. The second is a developed system - 3Smart EMS. Further in the paper will be presented informations first about the 3Smart project, then about both systems, about the experiment that shows the results of building energy management in both systems and finally the conclusion with special reference to the achieved results.

\section{International project 3Smart}

3Smart is a European project co-financed by the Danube International Interreg Program, which promotes cooperation in the countries of the Danube Region. This project was related to subjects in former DAAAM papers, i.e. [6]. A consortium with a total of 13 project partners and 5 associated strategic partners participated in the project. The leading project partner and conceptual creator of the project is Faculty of Electrical Engineering and Computing, University of Zagreb. The total value of the project for JP EPHZHB amounted to EUR 321,413.96, of which co-financing from the Danube International Program through the Instrument for Pre-Accession Assistance - IPA Fund in the amount of $85 \%$ of the project value. The total value of the project at the consortium level was EUR 3,791,343.41. The project lasted from January 1 st 2017 to December 31st 2019.

The main result of the project is the 3Smart Energy Management System platform - a software tool for building energy management in interaction with distribution networks. The pilot project in Bosnia and Herzegovina was realized on the location of the building in property of JP EPHZHB in Tomislavgrad. To achieve the main result of the project, it was necessary to upgrade the electrical, mechanical and IT installations of the building. The upgrade included the installation of a photovoltaic power plant with a power of $49,8 \mathrm{kWp}$ and a battery storage system with a capacity of $32 \mathrm{kWh}$ and converting power of $10 \mathrm{~kW}$ as well as the installation of various measuring and communication equipment.

There were many benefits of this project - fund withdrawal from EU programs and funds, gaining knowledge in working on European projects, acquiring professional skills through project activities, successful cooperation with renowned European institutions and promoting the use of renewable energy sources with energy efficiency.

\section{Building Energy Management System Desigo CC}

Building Energy Management System Desigo CC is a modern building management system used in a building in Tomislavgrad. The Desigo CC system is based on the SCADA platform. The system allows integration, monitoring and, where possible, management of specific physical quantities related to the building. Data is collected, stored in a database, processed and at the end the system manages certain parameters. The system collects data via sensors, room controllers, integration controllers and switches that are interconnected and forward information to a computer application.

The EPHZHB office building in Tomislavgrad has area of more than $1000 \mathrm{~m} 2$ (ground floor and first floor). The building has been in operation since 2013, and consists of office space, meeting room, control room, IT room and other auxiliary rooms. Two sources are used for preparing media for heating and cooling the space in the building: the primary energy source for heating and cooling is a heat pump, while the secondary energy source for heating is an electric thermoblock. The distribution of thermal energy in the building is performed using parapet fan coil units and ceiling fan coil units. For the meeting room on the ground floor and the room of the control center on the first floor, fresh air is provided via two air-conditioning chambers.

As already mentioned, to achieve the main result of the project, it was necessary to upgrade the electrical, mechanical and IT installations of the building. In addition to upgrading the installation, a new photovoltaic power plant with a capacity of $49,8 \mathrm{kWp}$ and a battery storage system with a capacity of $32 \mathrm{kWh}$ and converting power of $10 \mathrm{~kW}$ as well as various measuring equipment - temperature, flow, solar radiation sensors, current measuring transformers, etc. and communication equipment - controllers that take data from measuring devices and forward it to the central computer. Two computers were installed - on one computer the 3Smart EMS platform was installed and running, while on the other computer the Desigo CC platform was installed and running. The communication scheme of the system is shown in Figure 1 . 


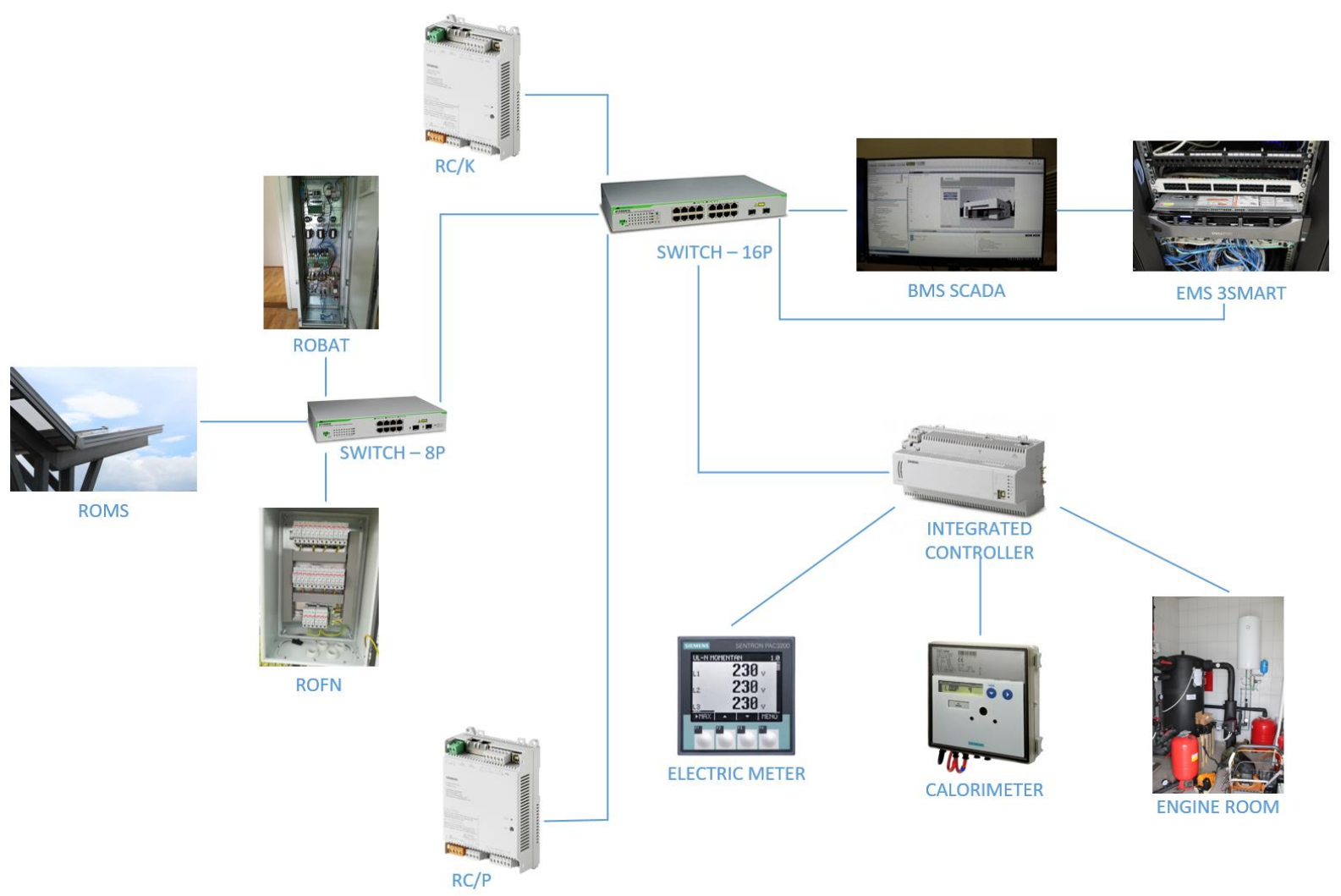

Fig. 1. System communication scheme

The basic communication scheme of the system is divided into several parts according to the location of installation of measuring and communication equipment. Measuring and communication equipment is located on the ground floor and first floor of the main building, in the auxiliary building where the battery system is located and as part of the photovoltaic power plant. The fan coil controllers are connected to the fan coil units in the office rooms, lobbies, meeting room on the ground floor and in the room of the control center on the first floor of the main building.

Electric meters which are in the main building refer to the total consumption of the building, and to the consumption of individual consumers: heat pump, electric thermo-block, air conditioning chamber for meeting room and air conditioning chamber for the control center. Electric meters were also installed as a part of the installation of the PV plant and in the auxiliary building for measuring the production and consumption of the battery system. The calorimeters installed in the main building refer to measurements of ground and first floor data and two air conditioning chambers. Calorimeters are also installed in the heating-cooling station of the building, inside which there are an electric thermoblock and an inertial tank connected to an external heat pump.

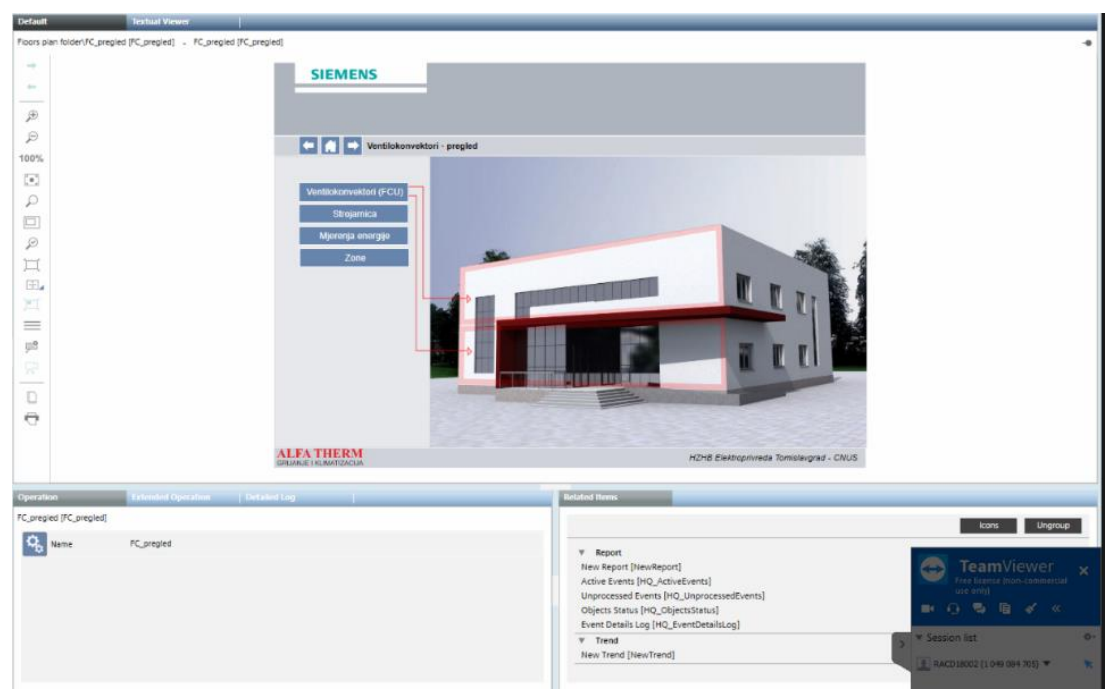

Fig. 2. Desigo CC graphical user interface 
The heat pump, electric thermo-block and inertial tank have separate calorimeters. Pyranometers are located on the roof surfaces of parking structures next to PV modules. Integration controllers that collect data from these devices are in the electrical cabinet located in the IT server room inside which are located the computers running Desigo CC and 3Smart EMS. Figure 2 shows the graphical user interface of the Desigo CC platform. During the implementation of the application, critical alarms, tabular (textual) display of used variables with dynamic symbols in the image and dynamic 3D \& HD graphics (clearly, aesthetically refined and effectively serve to display changes on the screen) are visible on the computer screen.

Desigo CC collects, displays, and manages:

- Air temperature in the rooms,

- Fan coil speed of the room fan coils,

- Starting temperature of the medium in the tank connected with the building consumers (setpoint temperature of the electric thermo-block),

- Setpoint of return medium temperature of the heat pump,

- $\quad$ Electric (thermal) power of the electric thermo-block.

Desigo CC collects and displays data (in addition to the above):

- $\quad$ Outside temperature,

- Calorimeter data - heating thermal energy, cooling thermal energy, thermal power, flow, return medium temperature, volume of the medium,

- Data from electric meters - active power, electrical energy, line voltages, phase voltages, currents by phases,

- Pyranometer data - global solar radiation.

The data is stored in the Desigo CC system database based on the change of the value of the variable. The connection between the 3Smart PostgreSQL database and building variables is realized through the so-called Smart Switch application. The application allows data to be written from the controller to the PostgreSQL database. Data is recorded at regular time intervals every 60 seconds.

\section{Building Energy Management System through interaction with the distribution network - 3Smart EMS}

3Smart EMS is the main result of the 3Smart project. The largest innovation of the project is in vertical bi-directional synchronization which is executed through modules with simple interfaces. Modules allow optimal operation of the building and grid and simple upgrade of those modules on existing management systems.

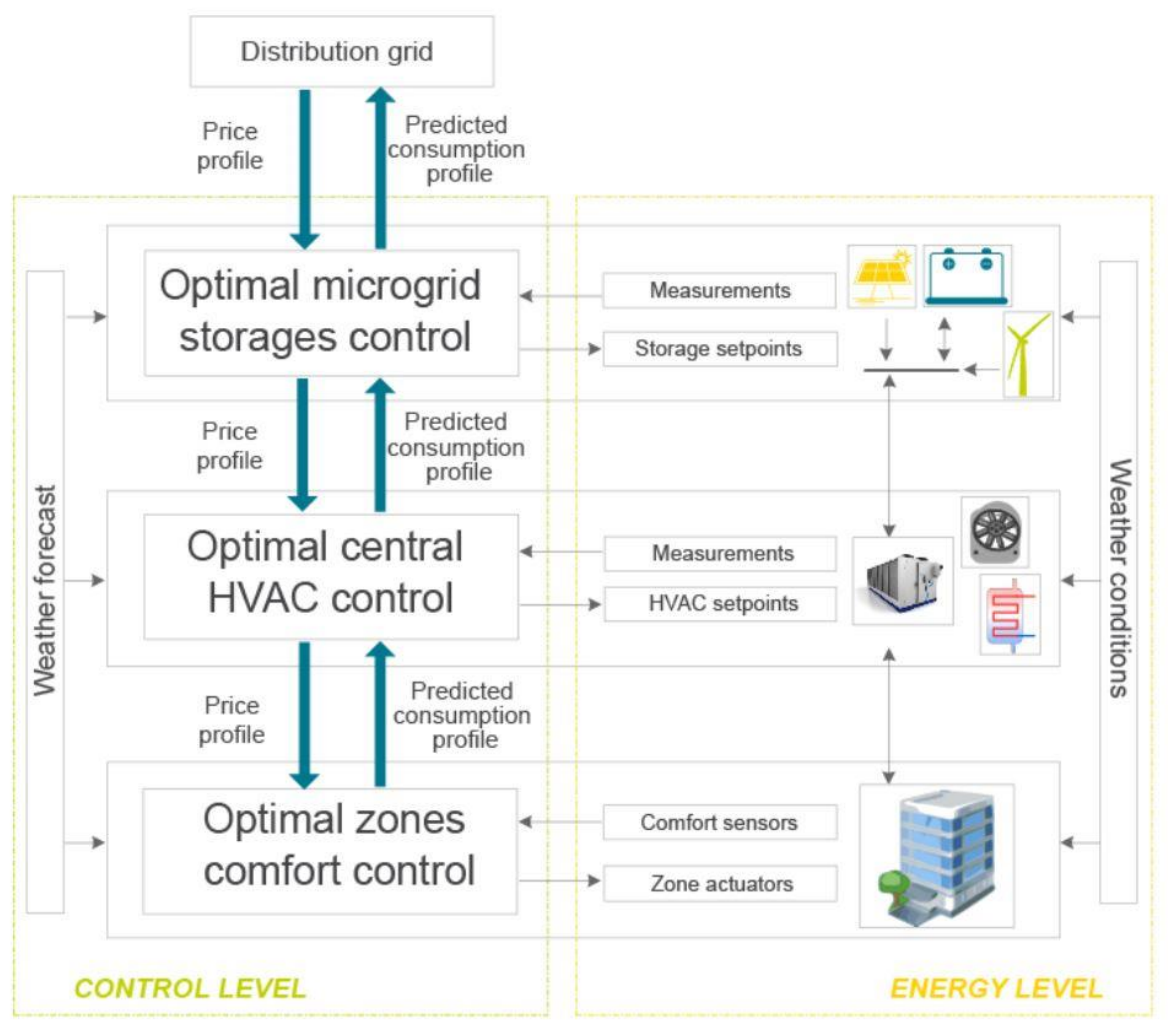

Fig. 3. Basic functional diagram of 3Smart building-side EMS 
The modules were developed during the project. Most of the modules were created by employees of the Faculty of Electrical Engineering and Computing, University of Zagreb. The basic functional diagram of the 3Smart building-side EMS is shown in Figure 3.

The modules are divided into Building-side modules and Grid-side modules (this refers to the electrical distribution network). Building-side modules consist of three levels specified by the vertical decomposition of the energy system [7]:

1) Zone level,

2) Central HVAC level, and

3) Microgrid level.

EMS decision making modules and submodules on specified levels rely on predictions and mathematical optimization of costs of comfort and energy. They are divided into three levels:
a) Prediction and Estimation,
b) Model Predictive Control, and
c) Interface.

The following building-side modules are installed on the server computer in Tomislavgrad:

1) Zone level:

- Z.PE.1 (Zone. Prediction \& Estimation. 1) - Fan coils identification submodule,

- Z.PE.4 - Submodule for identification of the simplified building thermal dynamics model,

- Z.PE.5 - Submodule for estimation of the states of the simplified building thermal dynamics model including also the estimation of heat disturbance in zone,

- Z.PE.6 - Submodule for prediction of the heat disturbance evolution per zone,

- Z.PE.7 - Submodule for prediction of the comfort setpoint in the zone,

- Z.MPC.1 (Zone. Model Predictive Control. 1) - Model predictive control module for zones comfort control,

- Z.I.1 (Zone. Interface. 1) - Interface module on zone level - Fan coils energy input control submodule.

2) Central HVAC level:

- HVAC.PE.1 (HVAC. Prediction \& Estimation. 1) - Submodule for the identification of a heat pump efficiency map,

- HVAC.PE.4 - Submodule for prediction of the total non-controllable consumption on the central HVAC unit,

- M.PE.6 - Submodule of identification of parameters of controlled consumers - buffer tank,

- HVAC.MPC.2 (HVAC. Model predictive control. 2) - Heating substation model predictive control submodule.

3) Microgrid level:

- M.PE.1 (Microgrid. Prediction \& Estimation. 1) - Submodule for identification of battery parameters,

- M.PE.2 - Submodule for estimation of battery state of charge,

- M.PE.3 - Submodule for prediction of the total non-controllable energy consumption on the microgrid level,

- M.PE.4 - Submodule for prediction of the photovoltaic array production,

- M.MPC.1 (Microgrid. Model predictive control. 1) - Model predictive control module for microgrid energy flows control,

- M.I.1 (Microgrid. Interface. 1) - Module for issuing commands towards the storage power converter based on the commanded energy exchange signals.

According to the name and description of each module, the purpose of the module is clearly defined, i.e. to which controllable part the module refers. The graphical user interface of the 3Smart EMS application does not currently exist, but it is planned to be developed in the near future. Figure 4 shows the organizational scheme of the Building-side modules.

3Smart EMS Grid-side modules are divided into short-term modules and long-term modules. Short-term modules are further divided into day-ahead and intra-day modules. Long-term modules are divided into annual and multi-annual modules. Operations performed by short-term and long-term modules are closely related. Long-term contracts, as a result of multi-annual module, are among other based on load forecasts and real-time measurements. Load forecasting and measuring in real time are the basis of the work of short-term modules. Load forecasting is used in assessment of flexibility needs of day-ahead, while the data measurement is starting trigger for flexibility of intra-day.

Grid-side modules are used as interaction between building module and distribution system operator. Based on the calculation, the distribution system operator sends a request to the building for flexibility, i.e. reducing the peak load of the building in this case. The building then decides whether it is worthwhile to offer the flexibility service through a reservation and activation fee and possibly activates the flexibility service. Activation of flexibility implies the use of electricity from the battery system, i.e. reducing the use of electricity from the distribution network. 


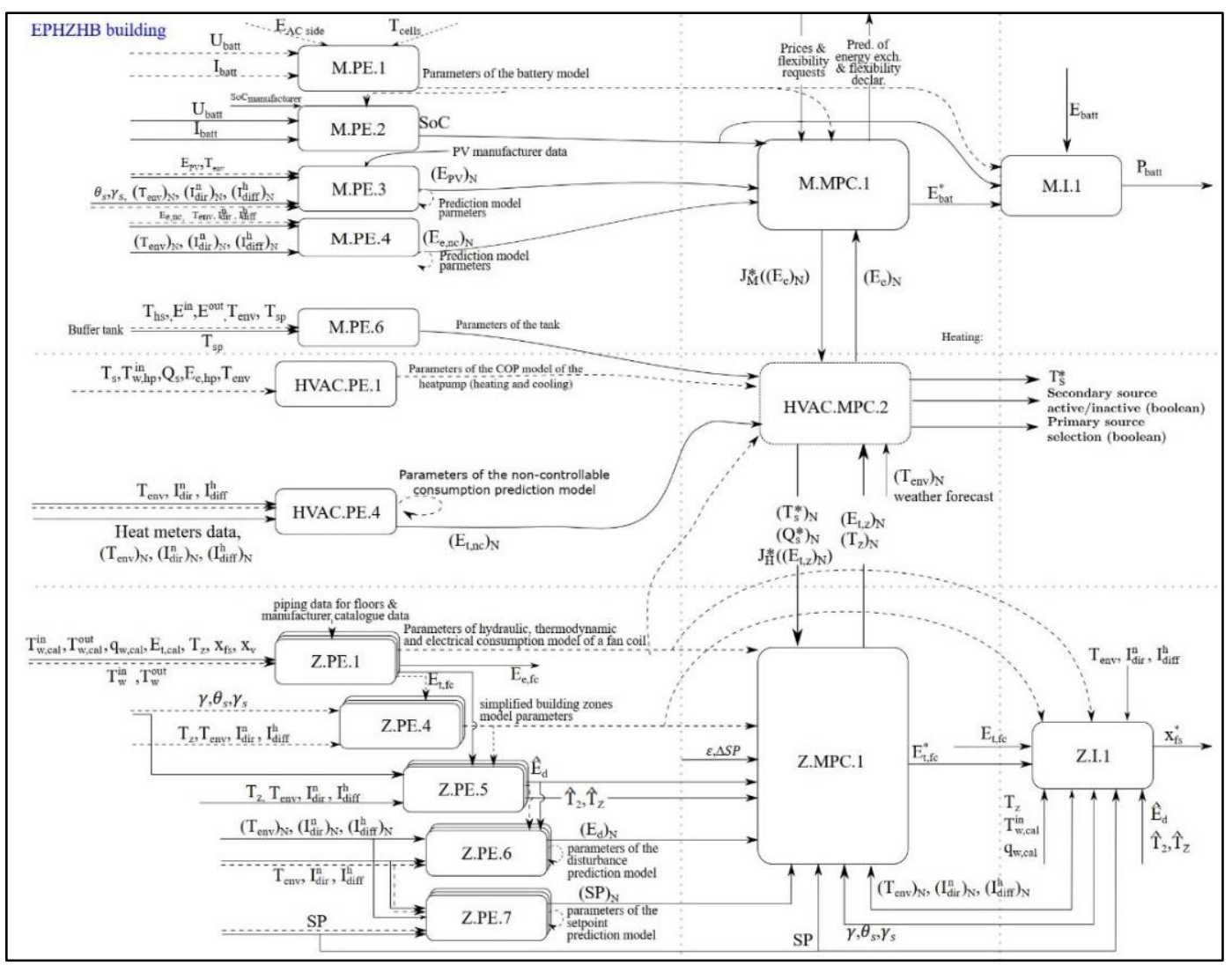

Fig. 4. Organization scheme of the Building-side modules

\section{Energy management comparison experiment}

To compare the results of energy management, an experiment was made where within the first working week of Tuesday July 14th 2020 until Thursday July 16th 2020 energy management was taken over by the 3Smart EMS platform while within the second working week from Tuesday July 21st 2020 until Thursday July 23rd 2020 energy management was taken over by the Desigo CC platform. The main analysed parameter is the electricity consumption of the building. It largely depends on the consumption of thermal energy. The primary source of energy for heating and cooling is a heat pump, while the secondary source of energy for heating is an electric thermo-block. The distribution of thermal energy in the building is done using parapet and ceiling fan coil units.

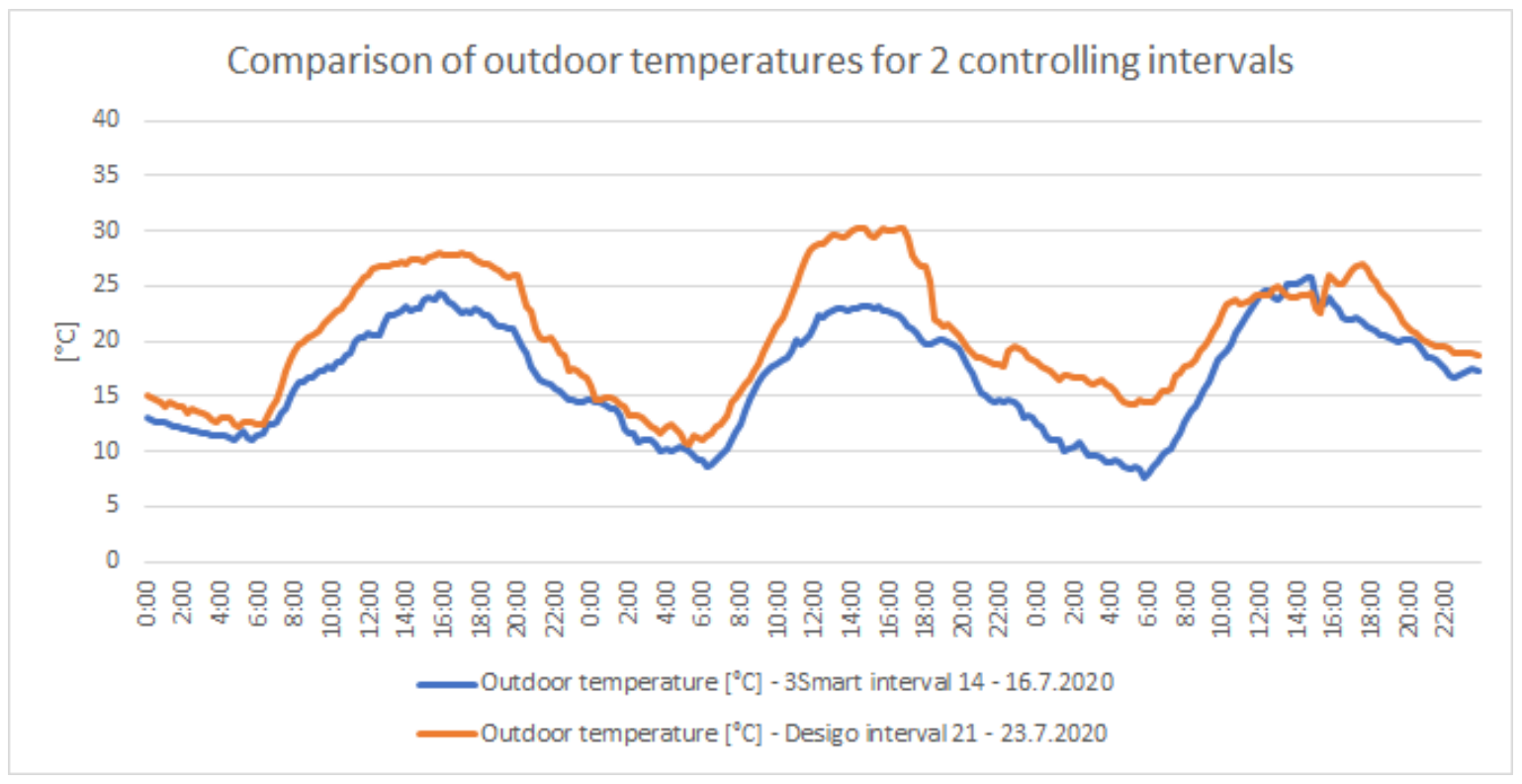

Fig. 5. Comparison of outdoor temperatures for 2 controlling intervals 


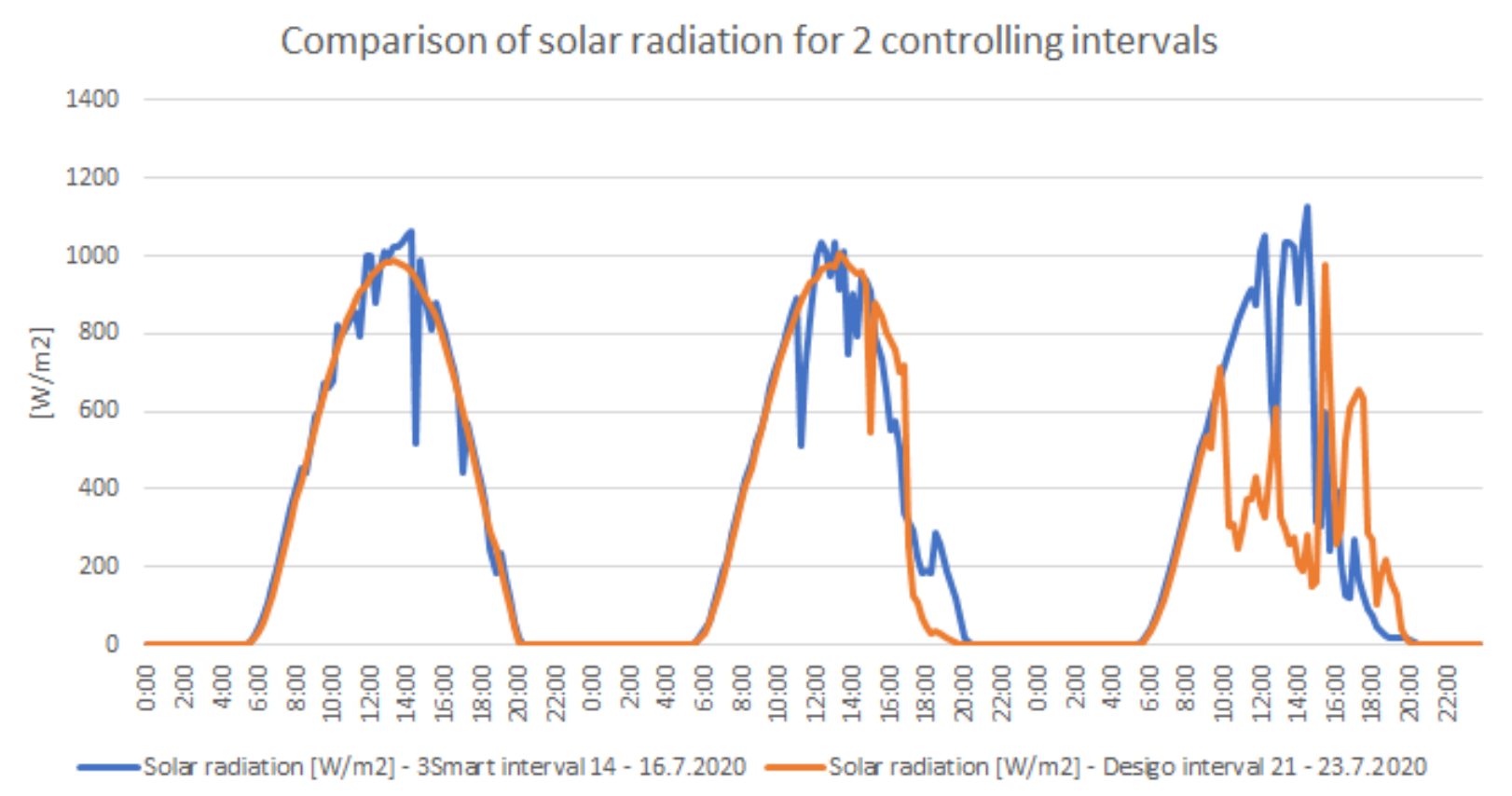

Fig. 6. Comparison of solar radiation for 2 controlling intervals

Thermal energy consumption is directly affected by the outside temperature and solar radiation. Also, it is important to know the habits of the energy consumers in the building as well as the used loads. There are 15 employees in the building during working hours from 8:00 am to 4:00 pm, whose working hours are from 8:00 am to 4:00 pm. In addition to these employees, 1 employee of the security company stays in the building throughout the day (from 00:00 am to 11:59 $\mathrm{pm})$. Electricity consumers in the transition period are computers, printers, interior lighting, air conditioning for the server room, fire alarm system, burglar alarm system, etc. During the analysed work weeks, consumers in the building used a heat pump for cooling. Figures 5 and 6 show a comparison of outdoor temperatures and solar radiation for 2 different control intervals.

Figure 5 shows that daytime temperatures are almost entirely a few degrees higher during the Desigo control interval. The solar radiation, Figure 6, is approximately the same when comparing first two days while on the third day the radiation is significantly higher in the case of the 3Smart control interval. Figure 7 shows a comparison of power consumption for two different control intervals.

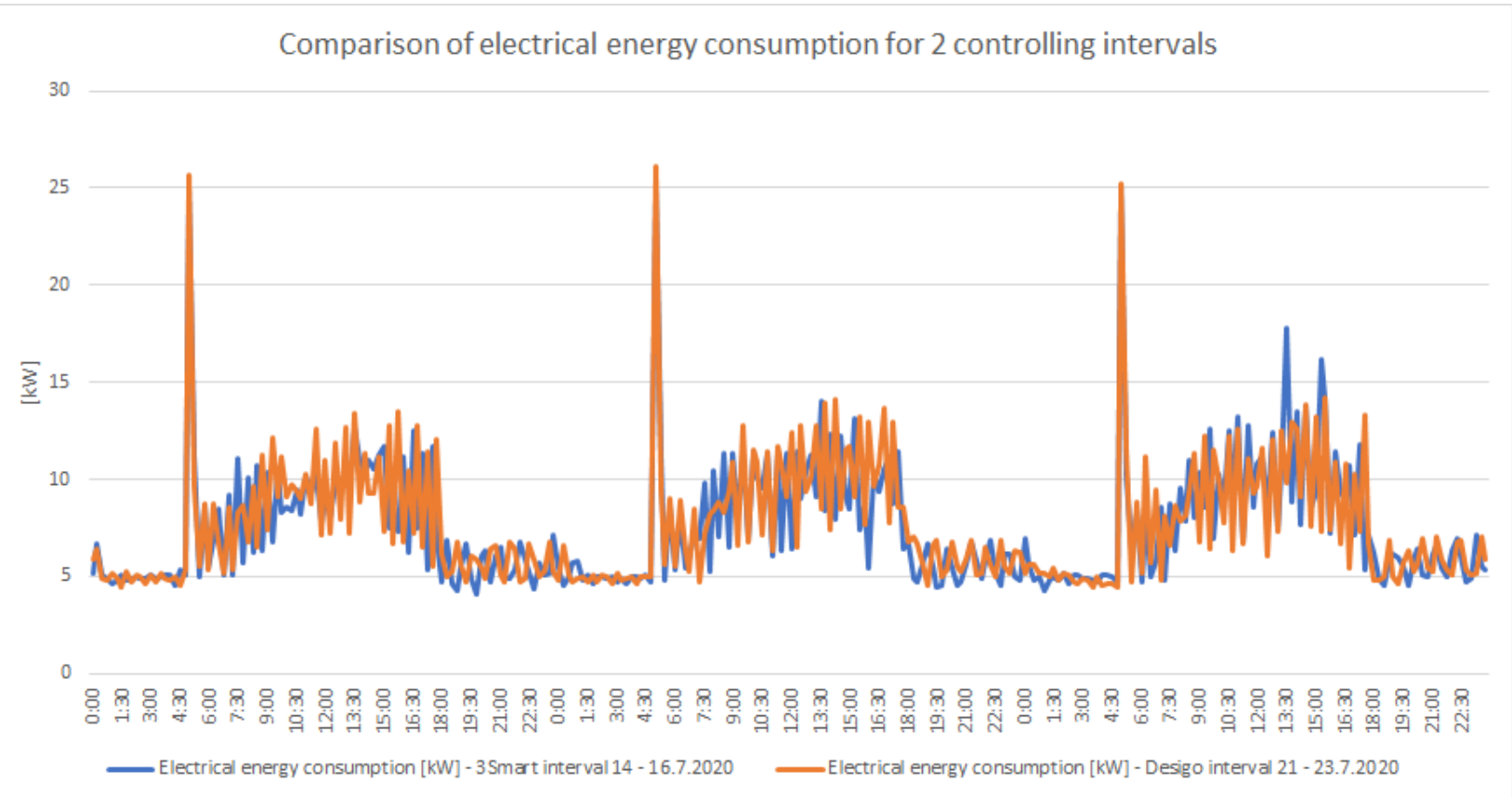

Fig. 7. Comparison of power consumption for two control intervals 
Figure 7 shows the noticeable peak of consumption that occurs at 5:00 am when the heat pump is started, which ensures the conditioning of the cooling medium during the cooling season. Furthermore, the increased consumption of electricity in the interval from 8:00 am to 4:00 pm is noticeable because this is the working time of all employees of the EPHZHB building except one employee of the security company. Total electricity consumption in $\mathrm{kWh}$ :

- $\quad 3$ Smart interval July 14th - 16th 2020: 544 [kWh]

- Desigo interval July 21st - 23rd 2020: 554 [kWh]

Electricity consumption in the case of energy management of the Desigo CC platform increased by approximately $2 \%$, i.e. consumption increased slightly. Approximately the same number of people was in the building in both cases; during 3Smart interval 12, during Desigo interval 13.

\section{Conclusion}

The energy management system defines the requirements for the establishment of energy management systems in industrial plants, commercial, administrative and government buildings and entire organizations. It is estimated that such systems, which are aimed at wider application in all national economic sectors, will affect about $60 \%$ of world energy use. The energy management system generally consists of a process that will control the energy consumption of the building with the preparation of action plans for energy consumption, setting targets for reducing energy consumption, monitoring energy consumption and developing energy efficiency indicators. Energy Management becomes new standard policy for leading companies within Industry 4.0 around the world [8]. In this paper, two different energy management systems installed in the office building of JP EPHZHB d.d. Mostar in Tomislavgrad are analyzed; one is the 3Smart EMS system which, as a result of the international project 3Smart, through the modules enable optimal operation of the building in interaction with the distribution network, and the second system presents the Desigo CC platform as the most comprehensive system for building energy management currently available on the market.

For better analysis in the paper, an experiment was made in which the energy consumption of the building was analyzed for two different cases. During the first working week, energy management was taken over by the 3Smart EMS platform, while during the second working week, energy management was taken over by the Desigo CC platform, and a comparison of electricity consumption for these two different management intervals was made. With small differences in the parameters that directly affect the consumption of thermal energy (outdoor temperature and solar radiation) for the observed two weeks, the consumption of electricity for two different control intervals according to the obtained results differs by $10 \mathrm{kWh}$. Namely, the consumption of electricity in the case of energy management of the Desigo CC platform increased by approximately $2 \%$, so in this case the 3Smart EMS system showed slightly better results. Otherwise, the advantages of 3 Smart systems that standard commercial management systems do not allow: hierarchical predictive control, openness to various configurations of existing management systems, easy upgrade to existing systems, forecasting conditions in the distribution network, weather forecast. However, the results obtained in the observed case do not mean there is lack of quality of Desigo CC, on the contrary, it is the most modern commercial energy management system in buildings on the market today.

In both cases, integrated building management systems can cover user requirements including control and optimization of various systems in the building. Future research plans include system analyses during heating season. This is especially important because of higher electrical energy consumption during heating season and accordingly higher importance in efficient use of energy.

\section{References}

[1] European Commission (2020). 2020 climate \& energy package, https://ec.europa.eu/clima/policies/strategies/2020_en\#tab-0-0, Accessed: 2020-07-27

[2] European Union (2019). Clean energy for all Europeans, March 2019

[3] Rhys Jones, S.; Beardmore J.; Gillot, M.; Boukhanof, R. \& Walker, G. (2018). A Control Methodology for Building Energy Management Systems (BEMS) in Heat Networks with Distributed Generation, Science Direct Energy Procedia 153 (2018) 295-302

[4] Molina-Solana, M.; Rosa, M.; Ruiz, D. M.; Gomez-Romero, J. \& Martin-Bautista, M.J. (2017). Data science for building energy management, Renewable and Sustainable Energy Reviews 70 (2017) 598-609

[5] Sayed K. \& Gabbar A. H. (2018). Energy Conservation in Residential, Commercial, and Industrial Facilities Chapter 2: Building Energy Management Systems, IEEE Press, 2018

[6] Crnokic, B.; Ljesic G.; Stojkic Z. \& Bandic-Glavas M. (2017). Analysis of Energy Consumption in the Building as the Basis for Development of the Modular Model Predictive Control, 28th DAAAM International Symposium on Intelligent Manufacturing and Automation, Zadar, November 2017

[7] Medjugorac, M. (2018). Realization of 3Smart project at EPHZHB business building site in Tomislavgrad, 1st conference BH K/O CIRED, Mostar, October 2018

[8] Medojevic, M.; Diaz-Villar P.; Cosic, I.; Rikalovic A.; Sremcev, N. and Lazarevic, M. (2018). Energy Management in Industry 4.0 Ecosystem: A Review on Possibilities and Concerns, 29th DAAAM International Symposium on Intelligent Manufacturing and Automation, Zadar, October 2018. 